\title{
The photoprotective effects of a food supplement tomato powder rich in phytoene and phytofluene, the colorless carotenoids, a preliminary study
}

\author{
Liki von Oppen-Bezalel ${ }^{1 *}$, Danit Fishbein ${ }^{1}$, Fabien Havas ${ }^{1}$, Olga Ben-Chitrit ${ }^{1}$ and Alain Khaiat ${ }^{2}$ \\ ${ }^{1}$ IBR Ltd, Pekeris 4,Rehovot, 7670204, Israel \\ ${ }^{2}$ Seers Consulting Pte. Ltd., 470 Sembawang Drive \#10-447, Singapore 750470, Singapore
}

\begin{abstract}
Background: Currently, protection against the damaging effects of UV radiation is most commonly accomplished by use of a topical sunscreen. This protection is effective but localized.

Objective: The aim of the present study was to determine if a food supplement comprised of a tomato powder rich in Phytoene and Phytofluene, the colorless carotenoids, could improve the natural protection of the skin against the sun, and bring other beauty and health benefits to the skin. Phytoene and Phytofluene absorb in the UV range; they also have antioxidant and anti-inflammatory properties.
\end{abstract}

Method: A group of 22 healthy female volunteers were given an oral supplement corresponding to an equivalent of 5 mg of Phytoene and Phytofluene a day for 12 weeks. Minimum Erythemal Dose (MED) was measured on the back of the volunteers after 6 and 12 weeks.

Results: Results show an average increase of $10 \%$ of the MED in all panelists; in $2 / 3$ of the panelists, an increase of $20 \%$ was observed after 12 weeks. Erythema after exposure to 1.25 MED was also measured, showing no increase in skin color. Skin quality was reportedly improved in 55-95\% of the volunteers (clinical and subjective assessment).

Conclusions: Our study, while limited in the number of panelists, shows that daily intake of these carotenoids protects the skin from UV radiation by increasing the MED and the skin's natural resistance to UV induced erythema.

\section{Introduction}

Sunlight is the main environmental factor influencing human skin. Numerous publications have shown the negative effects of UV Rays, including inflammation, elastosis, wrinkles, pigmentation disorders, melasma, or melanoma [1-4].

UV exposure results in direct damage to DNA (destruction) and indirect damage mediated by free radicals formed as a result of this exposure. It is commonly agreed among physicians that any skin-care or skin health strategy should include photoprotection as a leading element.

Sun avoidance is considered the most effective form of photoprotection, but it is not an available option for most. A usual compromise includes clothing, shading and sunscreen application, all delivering their effect externally, from the outer surface of the skin. We now introduce an additional photoprotective aid, delivering its effect from within the body onto the outer surface of the skin.

Damaging UV phenomena are undesirable across the full spectrum of organisms in nature, including humans, plants and yeasts. To battle these phenomena, exposed organisms have developed a variety of biological mechanisms. One example of such photoprotective mechanism, as seen in carotenogenic plants and microorganisms, is the production and accumulation of carotenoids in the exposed cells.

Carotenoids are a family of over 600 members able to absorb various parts of the sun light spectrum and quench free radicals generated in biological systems, as a result of UV radiation among other causes. As such they are a natural form of photoprotectants. Humans are not able to produce carotenoids but they are able to accumulate carotenoids from their diet [6]. Colored carotenoids such as Lycopene and $\beta$-carotene are already used in dietary supplements to protect the skin from lightinduced damage. Often, though, oral or topical use of these strongly colored carotenoids at concentrations delivering photoprotective effect will impart a yellow, orange or reddish coloration to the skin. Thus, the use of carotenoids devoid of visible color, which will therefore not directly affect skin color, yet impart a photoprotective benefit would be strongly preferred.

Phytoene and Phytofluene are members of the carotenoid family, being the precursors for all other carotenoids in nature. These carotenoids absorb light in the UV range, with Phytoene absorbing in the UVB range ( $\lambda$ max $287 \mathrm{~nm}$ ) and Phytofluene absorbing in the UVA ( $\lambda$ max $348 \mathrm{~nm}$ and $366 \mathrm{~nm}$ ); they do not absorb light in the visible range and are thus devoid of visible color, offering as will be shown here, a

Correspondence to: Liki von Oppen-Bezalel, IBR Ltd, Pekeris 4,Rehovot, 7670204, Israel, Tel: +49 30 80589698; Fax: +49 30 80589704; E-mail: LBezalel@ibrweb.com

Key words: carotenoids, phytoene, phytofluene, sun protection, UV light, skin claim substantiation, skin physiology, delivery

Received: July 26, 2015; Accepted: August 24, 2015; Published: August 26, 2015 
photoprotective effect without coloring the skin.

Other data supports that Phytoene and Phytofluene act as freeradical quenchers, DNA protectors and anti-inflammatory agents, offering relief of undesirable phenomena. Aust et al. have shown that supplementation of the diet with Lycopene or with tomato extracts comprising carotenoid mixtures of Lycopene, Phytoene and Phytofluene decreases erythema intensity after UV irradiation [5]. This effect was correlated to increased levels of the colorless carotenoids Phytoene and Phytofluene in the extracts.

Hatta et al. have shown that when added to the diet, Phytoene and Phytofluene tend to accumulate in the skin and therefore result in a higher concentration in the skin [6]. The accumulation of these carotenoids in the skin increases their availability to exert their photoprotective effect on the surface during UV exposure. Their UV absorbing, anti-oxidant and anti-inflammatory attributes offer a global photoprotective effect.

To assess in humans the photoprotective effect of orally consumed Phytoene and Phytofluene, a clinical study was conducted. The source for Phytoene and Phytofluene, a tomato powder rich in colorless carotenoids and poor in strongly colored carotenoids, namely PhytoflORAL ${ }^{\circ}$, was provided courtesy of IBR Ltd.

\section{Material and methods}

The clinical trial, an open intra-individual study where each subject is his own control, was conducted at Dermscan Poland from January 11 to April 12, 2013. The clinical trial was conducted according to the Helsinki Declaration (1964) and its successive updates, under GCP$\mathrm{ICH}$ compliance. Product safety was followed throughout the test period through the collection and reporting of adverse effects.

\section{Product}

A tomato powder rich in the colorless carotenoids, Phytoene and Phytofluene, was formulated into an oral supplement; the daily dose of the supplement was equivalent to $5 \mathrm{mg}$ of Phytoene and Phytofluene a day.

\section{Goals}

The primary goal was to assess the photoprotective effect of the study product by (a) determination of the MED of the skin of the subjects' back and observation of its evolution over the study duration; and (b) measurements of erythema on the subjects' back after exposure to $1.25 \mathrm{MED}$, and observation of this erythema's evolution over time.
A secondary goal was to assess skin quality parameters on the subjects' face such as dryness, roughness, suppleness, evenness of complexion and skin texture. Evaluation of skin quality parameters according to the secondary goal was performed separately both by an expert clinician and by study participants.

\section{Subjects}

The study was performed on 22 healthy female subjects aged 2040 having given their informed consent. The average age among the study population was $24 \pm 1$ year. All subjects recruited qualified as skin phototype II.

\section{Exclusion criteria}

Subjects which were either pregnant, lactating or presenting known allergies to food were excluded from the study as well as subjects suffering from systemic diseases using concurrent therapy that may interfere with the evaluations foreseen in the protocol.

\section{Localization of measures}

The MED was measured on the back, while clinical evaluation and self-evaluation were performed on the face of the panelists;

\section{MED determination}

The MED was measured on the back of the panelists before they started taking the supplement (D0), then after 41-42 days (22 subjects) and 83-84 days (20 subjects).

- UV source: Xenon lamp: Solar Light type Multiport 601-300W,Filter WG320 (1.25 mm).

- Spectrum: 290 to $400 \mathrm{~nm}$

- $\quad$ Radiated surface: Six holes (diameter $8 \mathrm{~mm}$ ).

The irradiation was done on days $-2,41$ and 83 while the measurements were done on days $-1,42$ and 84 (16 to 24 hours after irradiation).

The dose determined for MED at time -2 $\left(\mathrm{MED}_{-2}\right)$ was then used for the 1.25 MED exposure throughout the study.

$\mathrm{UV}$ exposure at 1.25 $\mathrm{MED}_{\mathrm{D}-2}$ :

- UV source: Xenon lamp: LS-1000 Solar Light type Monoport,Filter UVA+UVB

- Spectrum: 290 to $400 \mathrm{~nm}$<smiles>CC(C)=CCCC(C)=CCCC(C)=CCCC(C)CCCC(C)CCC=C(C)CCCC(C)C</smiles><smiles>CC(C)=CCCC(C)=CCCC(C)=CC=CC=C(C)C=CC=C(C)CCC=C(C)CCC=C(C)C</smiles>

Figure 1. Respective structures of Phytoene and Phytofluene. 


\section{Average clinical improvement of skin parameters}

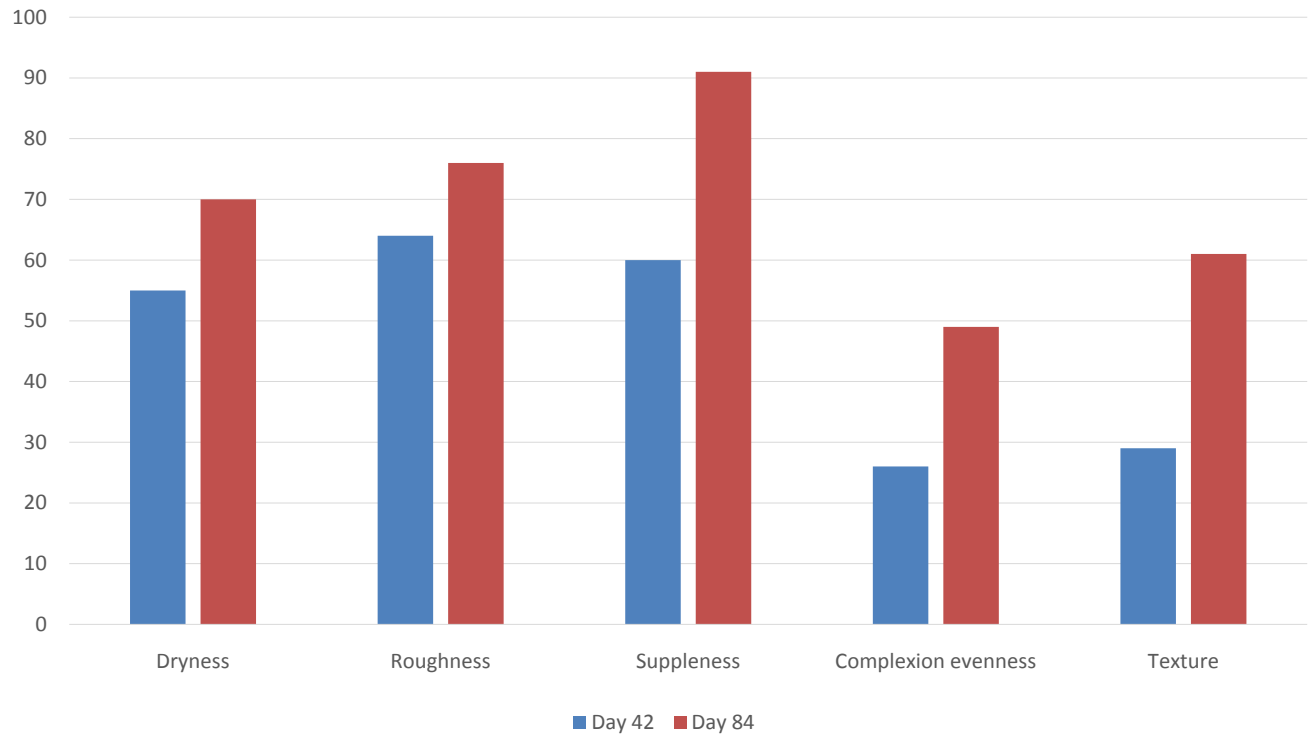

Figure 2. Graphic representation of the average changes in clinical scoring.

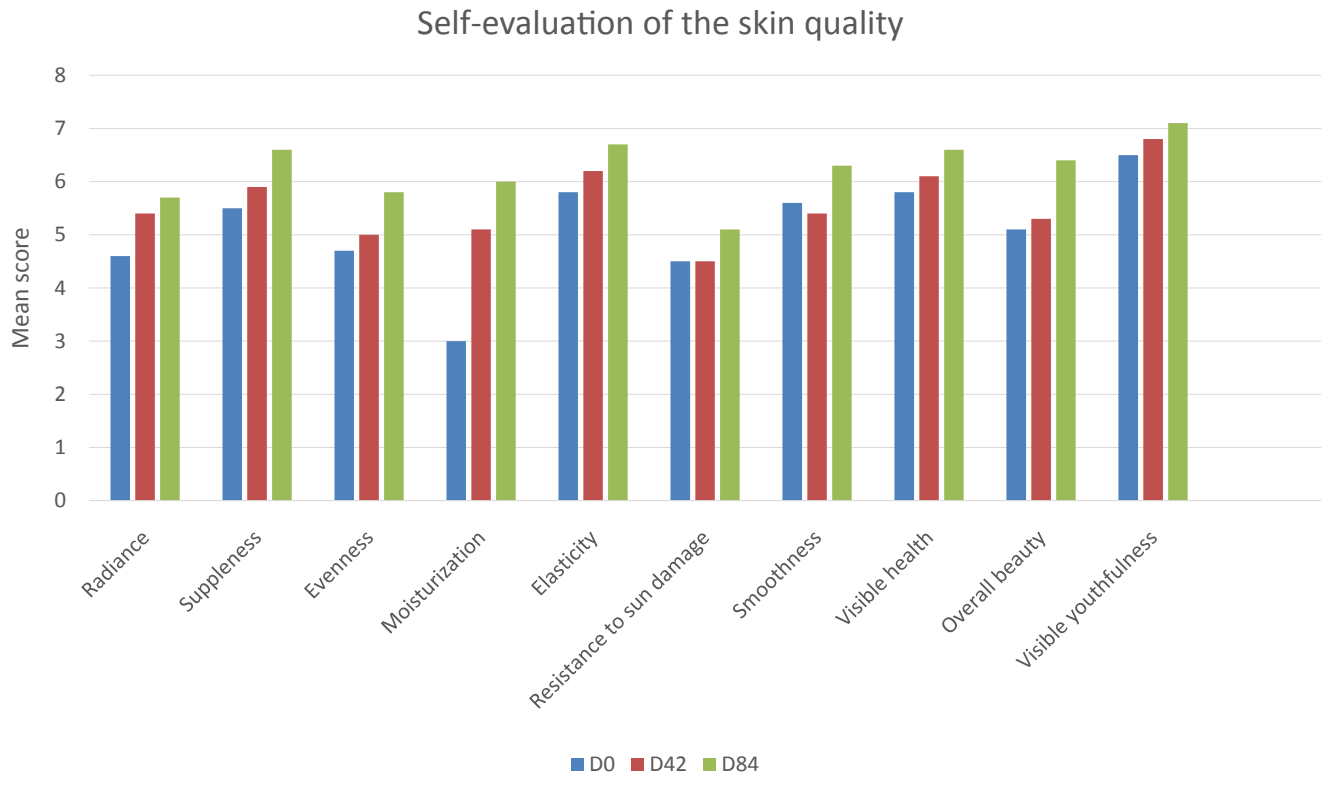

Figure 3. Self-evaluation of skin quality on a 10 points scale.

\section{- $\quad$ Radiated surface: $9 \mathrm{~cm}^{2}$}

At D1, D41 and D83 one UV exposure was done on a zone of $9 \mathrm{~cm}^{2}$ at the dose of $1.25 \mathrm{MED}_{2}$. The same dose was used at all subsequent study time points.

\section{Skin erythema}

The skin erythema was measured after irradiation with $1.25 \mathrm{MED}$ using a Minolta CM700-d Spectrocolorimeter ${ }^{\circledR}$ equipped with an $8 \mathrm{~mm}$ diameter head, at the same time intervals (respectively 19 and 18 subjects);
The Spectrocolorimeter ${ }^{\circledR}$ expresses colors perceived by the human eye as a digital code composed of three parameters:

- $\quad \mathbf{L}^{*}$ : for clarity (from dark to light),

- $\mathbf{a}^{\star}$ : for the green-to-red spectrum,

- $\mathbf{b}^{\star}$ : for the blue-to-yellow spectrum.

$\mathrm{a}^{*}$ and $\mathrm{b}^{*}$ are chrominance parameters and $\mathrm{L}^{*}$ is a luminance parameter.

Both $\mathrm{L}^{*}$ and $\mathrm{b}^{*}$ parameters are also exploited through the 
calculation of the Individual Typological Angle (ITA ${ }^{\circ}$, which defines the skin pigmentation degree of a subject according to the following formula:

$$
\operatorname{ITA}^{\circ}=\left[\operatorname{Arctan}\left(\left(L^{*}-50\right) / b^{\star}\right)\right] \times 180 / \pi
$$

The higher the $\operatorname{ITA}^{\circ}$ is, the lighter the skin is.

Measurements were done at each kinetics time point before and after exposure to $1.25 \mathrm{MED}_{\mathrm{D}-2}$. The difference between measurements before and after exposure was calculated. This difference was then compared between the basal measurement at D0 and the measurements at D42 and D84.

\section{Clinical scoring}

At each time point D0, D42, and D84 the investigator scored the panelists' facial skin using a 9 points scale for the following characteristics: dryness, roughness, suppleness, evenness of the complexion and skin texture.

\section{Self-assessment}

A subjective questionnaire was prepared, and filled by the panelists at the beginning (D0), at the middle (D42) and at the end (D84) of the study, to subjectively evaluate the efficacy of the product and its effects on skin characteristics. The subjective questionnaire was based on a ten point scale with 10 being best scoring per each parameter being evaluated, for example, evaluation of skin smoothness or hydration with 0 being very rough or very dry to 10 being very smooth or very hydrated respectively.

\section{Compliance}

One subject dropped out of the study because of a skin reaction apparently unrelated to the test product, and one subject was excluded because of excessive sun exposure during the study.

\section{Results}

\section{MED evolution}

The MED was unchanged after 42 days. However, after 84 days the MED increased significantly $(\mathrm{p}<0.01)$ by, on average, $10 \%$. The effect was noticeable in $65 \%$ of the subjects, which saw their MED value increase by an average of $20 \%$, while the remaining volunteers had no significant change (Table 1).
These results characterize a photo-protective effect and confirm indirectly that the colorless carotenoids Phytoene and Phytofluene, when ingested, concentrate into the skin. Further, the timings observed (lag time before significant MED increases are observed) give some insight into the kinetics of this accumulation, indicating that it is a relatively slow process.

\section{Spectrocolorimeter measurements}

After 42 and 84 days of product intake no significant variation of the spectrocolorimeter parameters was measured (Table 2). These results highlight and confirm that due to their lack of visible color, Phytoene and Phytofluene do not color the skin (as opposed to colored carotenoids like $\beta$-carotene or lycopene), at the same time providing a photoprotective effect while causing no skin darkening or reddening.

\section{Clinical scoring of skin quality}

Clinical scoring of the skin quality was significantly improved in 60 to $86 \%$ of the panelists after 42 days and in up to $90 \%$ of the panelists after 84 days (Table 3), across all parameters evaluated. Of particular interest, $95 \%$ of the subjects had improved skin evenness.

\section{Panelists' self- assessment}

The panelists' self-assessment confirmed the findings by the clinician above, showing perception of great improvement of skin quality parameters after 42 and 84 days of use including skin radiance, suppleness, evenness, smoothness, moisturization, elasticity, visible skin health, visible skin youthfulness, and overall skin beauty, as well as skin resistance to UV.

\section{Tolerance}

No relevant cutaneous symptom was observed or reported after 84 days of product intake.

One subject reported frequent and unusual headaches from day zero. She did not have headaches before and these stopped when she stopped the product on day 42 .

\section{Conclusions}

Under the study conditions, a food supplement containing a tomato powder rich in Phytoene and Phytofluene, the colorless carotenoids:

- $\quad$ Presented a significant photoprotective effect after 84 days

Table 1. Summary of MED measurements.

\begin{tabular}{|c|c|c|c|c|}
\hline Kinetics & $\begin{array}{c}\boldsymbol{\Delta} \\
(\mathbf{m e a n} \pm \mathbf{S E M})\end{array}$ & $\mathbf{\Delta \%}$ of the average & Student t-test p & Significant \\
\hline D42- D0 & 0.00 .02 & $0 \%$ & 0.961 & NO \\
\hline D84-D0 & $+0.09 \pm 0.03$ & $10 \%$ & 0.008 & YES \\
\hline
\end{tabular}

Table 2. summary of colorimetry measurements.

\begin{tabular}{|c|c|c|c|c|}
\hline Parameter & Kinetics & Variations (Mean \pm SEM) & Student t-test $p$ & Significant \\
\hline \multirow[t]{2}{*}{$\mathrm{L}^{*}$} & $\Delta \mathrm{D} 42$ & $-0.17 \pm 0.35$ & 0.628 & NO \\
\hline & $\Delta \mathrm{D} 84$ & $-0.13 \pm 0.27$ & 0.620 & NO \\
\hline \multirow[t]{2}{*}{$\mathrm{b}^{*}$} & $\Delta \mathrm{D} 42$ & $0.27 \pm 0.25$ & 0.293 & NO \\
\hline & $\Delta \mathrm{D} 84$ & $-0.20 \pm 0.26$ & 0.455 & NO \\
\hline \multirow[t]{2}{*}{$a^{*}$} & $\Delta \mathrm{D} 42$ & $0.20 \pm 0.35$ & 0.578 & NO \\
\hline & $\Delta \mathrm{D} 84$ & $0.01 \pm 0.26$ & 0.977 & NO \\
\hline \multirow[t]{2}{*}{$\mathrm{ITA}^{\circ}$} & $\Delta \mathrm{D} 42$ & $-1 \pm 0$ & 0.254 & NO \\
\hline & $\Delta \mathrm{D} 84$ & $0 \pm 1$ & 0.728 & NO \\
\hline
\end{tabular}


Oppen-Bezalel L (2015) The photoprotective effects of a food supplement tomato powder rich in phytoene and phytofluene, the colorless carotenoids, a preliminary study

Table 3. Summary of clinical scoring results.

\begin{tabular}{|c|c|c|c|c|c|c|}
\hline Cutaneous parameter & Kinetics & Variations (Mean \pm SEM) & $\begin{array}{c}\text { percentage variation of } \\
\text { the average }\end{array}$ & $\begin{array}{l}\text { Student } \\
\text { t-test p }\end{array}$ & Significant & $\begin{array}{c}\% \text { of subjects with the expected } \\
\text { effect }\end{array}$ \\
\hline \multirow[t]{2}{*}{ Dryness } & D42- D0 & $-0.5 \pm 0.1$ & $-55 \%$ & 0.002 & YES & $59 \%$ \\
\hline & D84-D0 & $-0.6 \pm 0.2$ & $-70 \%$ & 0.03 & YES & $55 \%$ \\
\hline \multirow[t]{2}{*}{ Roughness } & D42- D0 & $-0.9 \pm 0.1$ & $-64 \%$ & $<0.001$ & YES & $86 \%$ \\
\hline & D84-D0 & $-0.9 \pm 0.2$ & $-76 \%$ & $<0.001$ & YES & $90 \%$ \\
\hline \multirow[t]{2}{*}{ Suppleness } & D42- D0 & $-0.9 \pm 0.1$ & $-60 \%$ & $<0.001$ & YES & $86 \%$ \\
\hline & D84-D0 & $-1.3 \pm 0.1$ & $-91 \%$ & $<0.001$ & YES & $90 \%$ \\
\hline \multirow[t]{2}{*}{ Evenness of complexion } & D42- D0 & $-0.5 \pm 0.1$ & $-26 \%$ & $<0.001$ & YES & $64 \%$ \\
\hline & D84-D0 & $-1 \pm 0.1$ & $-49 \%$ & $<0.001$ & YES & $95 \%$ \\
\hline \multirow[t]{2}{*}{ Texture } & D42- D0 & $-0.6 \pm 0.1$ & $-39 \%$ & $<0.001$ & YES & $77 \%$ \\
\hline & D84-D0 & $-1.2 \pm 0.2$ & $-61 \%$ & $<0.001$ & YES & $90 \%$ \\
\hline
\end{tabular}

of product use as observed in the significant increase of the Minimum Erythemal Dose (MED) by, on average, 10\%. The effect was noticeable in $65 \%$ of the subjects which saw their MED value increase by $20 \%$;

- Induced a significant improvement in skin quality after 42 and 84 days of use shown by:

- Clinical scoring by the dermatologist: significant improvement in skin dryness, roughness, suppleness, evenness and texture;

- Subjective evaluation questionnaire completed by the subjects: improvement in skin radiance, evenness, hydration, smoothness, suppleness, elasticity and irritability. Study subjects found their skin more resistant to sun damage, more beautiful and visibly younger and healthier;

- Was globally well tolerated with no relevant cutaneous side effects. A single subject suffered from possibly product-related headaches.

The number of subject was too small for a full assertion of the effect and a further study with more subjects will be advisable. Nevertheless the study provides direct evidence that dietary supplements containing a tomato powder rich in the colorless carotenoids Phytoene and Phytofluene, can help protect the skin against UV damage, providing a significant photoprotective effect. The increase in MED also shows that these colorless carotenoids do migrate and accumulate into the skin and help improve the skin's general condition, as shown by substantial improvements in both clinical and self-evaluation of the skin.

\section{Acknowledgements}

The study was financed by IBR.

The research leading to these results was funded in part from the European Community's Seventh Framework Program (FP7/20072013) under grant agreement 613513 (Project DISCO).

\section{References}

1. Helfrich YS, Sachs DL, Vorhees JJ (2008) Overview of skin aging and photoaging. Dermatology Nurs 20: 177-183. [Crossref]

2. Bernstein EF, Chen YQ, Kopp JB, Fisher L, Brown DB, et al. (1996) Long term sun exposure alters the collagen of the papillary dermis: comparison of sun-protected and photoaged skin by Northern analysis, immunohistochemical staining and confocal laser scanning microscopy. J Am Academy of Dermatology 34: 209-218. [Crossref]

3. Green A, Whiteman D, Frost C, Battistutta D (1999) Sun exposure, skin cancers and related skin conditions. J Epidemiol 9: 7-13. [Crossref]

4. Schwartz E, Cruickshank FA, Christensen CC, Perlish JS, Lebwohl M, et al. (1993) Collagen alterations in chronically sun-damaged human skin. Photochem Photobio 58: 841-844. [Crossref]

5. Aust O, Stahl W, Sies H, Tronnier H, Heirich U (2005) Supplementation with tomatobased product increase Lycopene, Phytoene and Phytofluene levels in human serum and protects against UV-light-induced Erythema. Int J Vit Nutr Res 75: 54-60. [Crossref]

6. Hata TR, Scholz TA, Ermakov IV, McClane RW, Khachik F, et al. (2000) Noninvasive Raman spectroscopic detection of carotenoids in human skin. J Inv Derm 115: 441-448. [Crossref]

Copyright: (C2015 Oppen-Bezalel L. This is an open-access article distributed under the terms of the Creative Commons Attribution License, which permits unrestricted use, distribution, and reproduction in any medium, provided the original author and source are credited. 